\title{
Antipyrine clearance per unit volume liver: an assessment of hepatic function in chronic liver disease
}

\author{
M. HOMEIDA, C. J. C. ROBERTS, M. HALliwell, A. E. READ, AND R. A. \\ BRANCH \\ From the Departments of Medicine and Physics, Bristol Royal Infirmary, Bristol, England and the \\ Division of Clinical Pharmacology, Vanderbilt University School of Medicine, Nashville, Tennessee, USA
}

SUMMARY Liver size has been estimated clinically and by a non-invasive ultrasound technique in 16 normal subjects, 16 patients with cirrhosis, 10 patients with chronic biliary obstruction, and three patients with primary hepatoma. Antipyrine disposition was also measured in each subject. Hepatomegaly was not clinically detectable until there was approximately a $20 \%$ increase in liver size. Additional increases in size correlated significantly with clinical estimates of hepatomegaly. Antipyrine clearance had a three-fold range in normal subjects. Its mean value was significantly reduced in each subgroup of patients with liver disease. However, $48 \%$ of patients with liver disease had values within the normal range. In normal subjects there was a significant correlation between antipyrine clearance and liver volume. Thus, intersubject variation in clearance normalised for liver volume was less than clearance alone. Antipyrine clearance normalised for liver volume in patients with liver disease was significantly lower than in normal subjects and there was no overlap with normal subjects. In conclusion, assessment of drug metabolising efficiency per unit volume of liver increased the discrimination in differentiating subjects with normal from abnormal livers.

There is now clear evidence that the pharmacokinetic disposition of a large number of drugs is abnormal in patients with chronic liver disease (Hoyumpa et al., 1978) because the disease process influences both drug disposition (Branch et al., 1976a) and drug elimination (Wilkinson and Schenker, 1975). As drug clearance is a measure of the efficiency of the removal process it is possible that estimation of this parameter in an appropriate drug might provide a clinically useful functional assessment of the degree of hepatic damage. Antipyrine is a drug which has been extensively used in studies on interindividual variation in drug metabolising activity (Vesell and Page, 1968; Kolmodin et al., 1969; Vestal et al., 1975; Roberts et al., 1976) and in several studies in patients with liver disease (Branch et al., 1973; Andreasen et al., 1974; Noordhock et al., 1975; Andreasen and Greisen, 1976; Farell et al., 1976; Branch et al., 1976b; Sotaniemi et al., 1977a). Its advantages include complete absorption when administered orally (Andreasen and Vessel, 1974),

Received for publication 5 January 1979 slow but complete metabolism in the liver and negligible protein or tissue binding (Brodie and Axelrod, 1950). These characteristics result in a negligible first pass effect and result in its elimination being purely a reflection of drug metabolising activity or free intrinsic clearance (Wilkinson and Shand, 1975). Its disadvantage is the wide variation in clearances of normal subjects. In liver disease estimates of mean clearance have been reduced when groups of patients with liver disease have been compared with normal control subjects. However, the wide interindividual variation in normal subjects results in a considerable overlap in clearance between normal subjects and patient populations. This has reduced the value of antipyrine clearance as a discriminating test of hepatic function.

A feature common to most chronic liver diseases is infiltration of the liver with inflammatory or neoplastic cells resulting in hepatomegaly. Even if hepatocytes are undamaged, this will result in a reduced concentration of drug metabolising enzymes. If hepatocyte damage is present then the specific activity of the liver for drug metabolism will be even 
further reduced. Several studies have confirmed reductions in cytochrome $\mathbf{P}_{450}$ and drug metabolising activity in liver biopsies in patients with cirrhosis (Schoene et al., 1972; Farrell et al., 1976; Sotaniemi et al., 1977). However, this involves an invasive procedure and extrapolation of kinetic information obtained from in vitro studies of homogenised tissue to in vivo kinetics is potentially hazardous. An alternative is to measure liver mass in man and relate it to in vivo drug clearance. The objective of the present study has been to use recently developed non-invasive methods for estimating liver volume using ultra-sound together with measuring the pharmacokinetics of antipyrine to test whether it might be possible to obtain a more discriminative index of hepatic function.

\section{Methods}

\section{SUBJECTS}

Sixteen healthy, drug-free normal subjects selected to provide a group of similar age to patients with cirrhosis and 29 patients with chronic liver disease as listed in Table 1 consented to take part in the study, which had been approved by the Hospital Ethical Committee. No patient with cirrhosis had had portacaval surgery. None of the subjects was on drugs known to induce drug metabolism and only two patients with cirrhosis smoked. Clinical assessment included routine biochemical liver function tests, the estimation by the same clinician of hepatic size by palpation in centimetres below the right costal margin in inspiration, and quantitative estimation of the liver volume using the ultrasound method of Roberts et al. (1976).

Antipyrine $(1200 \mathrm{mg})$ was administered orally as a freshly prepared solution after an overnight fast and the withdrawal of $10 \mathrm{ml}$ of control venous blood. Subsequently, blood samples were drawn at three, six, nine 12 , and 24 hours in normal subjects and also 36, 48, and 72 hours in patients with liver disease. Food was withheld for the initial two hours after antipyrine administration. Plasma was separated by centrifugation and stored at $-30^{\circ} \mathrm{C}$ until later analysis using the method of Brodie and Axelrod (1950). Antipyrine half-life $\left(T_{\frac{1}{2}}\right)$ was estimated by least squares regression analysis of log plasma concentration with respect to time. The apparent volume of distribution (Vd) was estimated as:

$$
\mathrm{Vd}=\frac{\text { Dose }}{\mathrm{C}_{\mathrm{P}_{(\mathrm{o})}}} \quad \text { Equation } 1
$$

where $\mathrm{C}_{\mathbf{P}_{(o)}}$ is the back extrapolated plasma concentration at time zero. Clearance $(\mathrm{Cl})$ was calculated from:

$$
\mathrm{C} 1=\mathrm{Vd} \times \frac{0.693}{\mathrm{~T}_{\frac{1}{2}}} \quad \text { Equation } 2
$$

\section{Results}

The serum albumin concentration and prothrombin index were lower and the serum glutamic oxaloacetic transaminase was higher than in controls to an equivalent extent in each patient group (Table 1). Serum bilirubin and alkaline phosphatase were raised in each group, the increase being greatest in patients with primary biliary cirrhosis and extrahepatic obstructive jaundice.

The liver was not clinically palpable in any normal subject but was palpable in almost all patients. The clinical estimate of extent of hepatomegaly correlated significantly with liver volume measured by ultrasound (Fig. 1). However, within each of the clinical estimates of liver size there was an appreciable range of variation in liver volume. In normal subjects, liver volume and body weight were significantly correlated (liver volume $=102+19.8 \mathrm{wt}$, $r=+0.68, \mathrm{P}<0.004)$. This relationship was used to predict the expected liver weight of patients with liver disease (Table 2). Clinically detectable hepatomegaly was associated with an approximately $20 \%$ increase in liver volume. This represented an increase

\begin{tabular}{|c|c|c|c|c|c|c|}
\hline \multirow[b]{2}{*}{$n$} & \multicolumn{2}{|l|}{ Controls } & \multicolumn{2}{|l|}{ Cirrhosis } & \multirow{2}{*}{$\begin{array}{l}\text { Hepatomas } \\
3\end{array}$} & \multirow{2}{*}{$\begin{array}{l}\begin{array}{l}\text { Obstructive } \\
\text { jaurdice }\end{array} \\
5\end{array}$} \\
\hline & 16 & $\begin{array}{l}\text { Alcoholic } \\
8\end{array}$ & $\begin{array}{l}\text { Cryptogenic } \\
8\end{array}$ & $\begin{array}{l}\text { Primary biliary } \\
5\end{array}$ & & \\
\hline $\begin{array}{l}\text { Age (yr) } \\
\text { Weight (kg) } \\
\text { Albumin (g/1) } \\
\text { Prothrombin index (\%) } \\
\text { SGOT (IU) } \\
\text { Bilirubin (nmol/l) } \\
\text { Alkaline phosphatase } \\
\quad(\mathrm{U} / \mathrm{l})\end{array}$ & $\begin{array}{l}49.0 \pm 5.4 \\
64.0 \pm 2.0 \\
45.4 \pm 1.0 \\
97.8 \pm 0.6 \\
11.2 \pm 0.5 \\
10.4 \pm 1 \cdot 1 \\
70.0 \pm 14.0\end{array}$ & $\begin{array}{r}54.0 \pm 4.4 \\
64 \cdot 0 \pm 6 \cdot 0 \\
34.5 \pm 1 \cdot 8^{*} \\
71 \cdot 5 \pm 4 \cdot 0^{*} \\
80.0 \pm 44 \cdot 0^{*} \\
69.1 \pm 23 \cdot 0^{*} \\
154.0 \pm 28 \cdot 0^{*}\end{array}$ & $\begin{array}{c}62.0 \pm 2.9 \\
68.0 \pm 4.0 \\
35.4 \pm 2.6^{*} \\
85.3 \pm 4.8^{*} \\
43.0 \pm 4.5^{*} \\
28.9 \pm 4.6^{*} \\
252.0 \pm 49.0^{*}\end{array}$ & 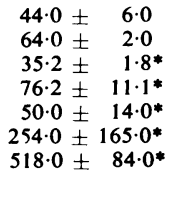 & 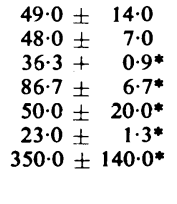 & 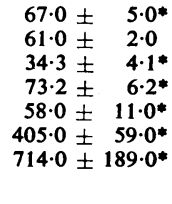 \\
\hline
\end{tabular}

Table 1 Clinical and liver function characteristics of normal subjects and patients with chronic liver disease

Mean \pm SEM. $\quad{ }^{*} \mathbf{P}<0.05$ compared with control. 
Table 2 Relationship between clinical assessment of liver size and liver volume measured by ultrasound in normal subjects and patients with chronic liver disease

\begin{tabular}{|c|c|c|c|c|}
\hline Clinical estimate of liver size & $n$ & Liver volume & Liver volume as $\%$ of body weight & $\%$ Change from expected liver volume \\
\hline $\begin{array}{l}\text { Liver not palpable } \\
\text { Liver just palpable }(1-2 \mathrm{~cm}) \\
\text { Moderate hepatomegaly }(3 \mathrm{~cm}) \\
\text { Marked hepatomegaly }\end{array}$ & $\begin{array}{r}18 \\
9 \\
13 \\
5\end{array}$ & $\begin{array}{l}1170 \pm 60 \\
1462 \pm 105^{*} \\
1897 \pm 117^{*} \\
3437 \pm 439^{*}\end{array}$ & $\begin{array}{l}1 \cdot 84 \pm 0 \cdot 075 \\
2 \cdot 26 \pm 0 \cdot 14^{*} \\
3 \cdot 32 \pm 0 \cdot 30^{*} \\
5 \cdot 17 \pm 0 \cdot 69^{*}\end{array}$ & $\begin{array}{l}-3 \cdot 0 \pm 4 \cdot 0 \\
+19 \cdot 5 \pm 7 \cdot 4^{*} \\
+70 \cdot 0 \pm 13 \cdot 0^{*} \\
+174 \cdot 0 \pm 33 \cdot 0^{*}\end{array}$ \\
\hline
\end{tabular}

Mean \pm SEM.

The percentage change from the expected liver volume was calculated from the relationship between liver volume and body weight obtained in normal subjects.

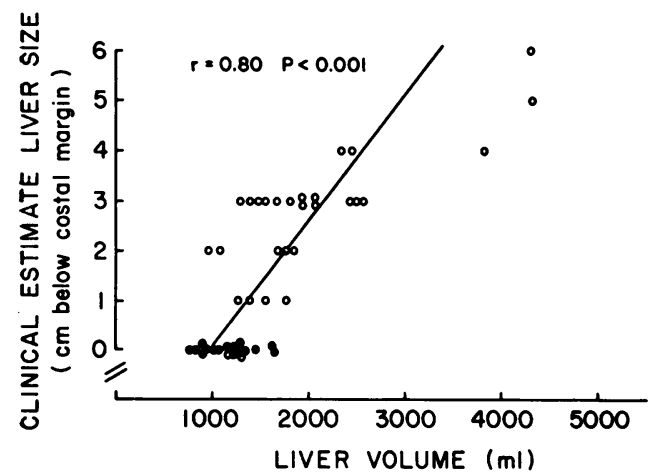

Fig. 1 The relationship between liver volume measured by ultrasound and clinical estimates of hepatomegaly, measuring the distance below the right costal margin on inspiration in normal subjects $(0)$ and patients with chronic liver disease $(O)$.

in the size of liver when expressed as a percentage of total body weight from $1 \cdot 84 \%$ to $2 \cdot 26 \%$, assuming a specific gravity of liver of $1 \cdot 0$. Moderate hepatomegaly-that is, $3 \mathrm{~cm}$ enlargement-was associated with an increase in liver volume of approximately $70 \%$, and marked hepatomegaly-that is, greater than $3 \mathrm{~cm}$ enlargement-was associated with a greater than three-fold increase in volume. Three patients died from hepatic failure shortly after the investigation. In eachinstance liver weight at necropsy was almost identical with liver volume measured in life by ultrasound (Table 3).

Antipyrine disposition was abnormal in each of

Table 3 Comparison between liver volume as measured by ultrasound method and necropsy liver weight

\begin{tabular}{|c|c|c|c|}
\hline & $\begin{array}{l}\text { Liver volume } \\
(\mathrm{ml})\end{array}$ & $\begin{array}{l}\text { Necropsy liver weight } \\
(\mathrm{g})\end{array}$ & $\begin{array}{l}\text { Histological } \\
\text { diagnosis }\end{array}$ \\
\hline I & 2047 & 2012 & $\begin{array}{l}\text { Primary biliary } \\
\text { cirrhosis }\end{array}$ \\
\hline II & 969 & 975 & $\begin{array}{l}\text { Alcoholic } \\
\text { cirrhosis }\end{array}$ \\
\hline III & 1730 & 1652 & $\begin{array}{l}\text { Chronic active } \\
\text { hepatitis }\end{array}$ \\
\hline
\end{tabular}

the groups studied (Table 4). Antipyrine clearance was reduced to an equivalent extent in each of the patient subgroups compared with control subjects. Considering all the patients with liver disease as a single group, antipyrine clearance correlated significantly with serum albumin and the prothrombin index but not other indices of hepatic function (Table 5). The volume of distribution of antipyrine was similar in each patient subgroup and correlated significantly with body weight (volume of distribution $=7.58+0.47 \mathrm{wt}, r+0.63, \mathrm{P}<0.001)$ when all subjects investigated were considered. The differences in clearance with no change in distribution resulted in significant increases in half-life for each patient subgroup.

Table 4 Estimates of hepatic size and antipyrine pharmacokinetics in normal subjects and patients with chronic liver disease

\begin{tabular}{|c|c|c|c|c|c|c|c|c|c|c|c|}
\hline \multirow[b]{2}{*}{$n$} & \multicolumn{3}{|l|}{ Controls } & \multicolumn{4}{|l|}{ Cirrhosis } & \multirow{2}{*}{\multicolumn{2}{|c|}{ Hepatoma }} & \multirow{2}{*}{\multicolumn{2}{|c|}{$\begin{array}{l}\text { Obstructive } \\
\text { jaundice } \\
5\end{array}$}} \\
\hline & 16 & $\begin{array}{l}\text { Alcoholic } \\
8\end{array}$ & & $\begin{array}{l}\text { Cryptogeni } \\
8\end{array}$ & & $\begin{array}{l}\text { Primary } b \\
5\end{array}$ & iliary & & & & \\
\hline $\begin{array}{l}\text { Clinical estimate liver size } \\
\text { (cm below rt costal margin) }\end{array}$ & 0 & $3 \cdot 3 \pm$ & 0.6 & $2 \cdot 3 \pm$ & 0.3 & $1 \cdot 8 \pm$ & $0 \cdot 7$ & $3 \cdot 3 \pm$ & 0.4 & $2 \cdot 4 \pm$ & $0 \cdot 2$ \\
\hline Liver volume $(\mathrm{ml})$ & $1163.0 \pm 67.0$ & $2451.0 \pm$ & $443 \cdot 0 * 1$ & $1729 \cdot 0 \pm$ & $137 \cdot 0 * 1$ & $783.0 \pm 2$ & $216 \cdot 0 * 23$ & $345.0 \pm$ & $759 \cdot 0 * 16$ & $613.0 \pm 2$ & $29.0 *$ \\
\hline $\begin{array}{l}\text { Antipyrine clearance } \\
(\mathrm{ml} / \mathrm{min})\end{array}$ & $36.5 \pm 2.9$ & $17.6 \pm$ & $3 \cdot 4^{*}$ & $22.4 \pm$ & $2 \cdot 6^{*}$ & $16.8 \pm$ & $2 \cdot 9^{*}$ & $17 \cdot 7 \pm$ & $2 \cdot 8^{*}$ & $17 \cdot 9 \pm$ & $3 \cdot 5^{*}$ \\
\hline $\begin{array}{l}\text { Antipyrine volume of } \\
\text { distribution }(1 / \mathrm{kg})\end{array}$ & $0.59 \pm 0.02$ & $0.64 \pm$ & 0.04 & $0.55 \pm$ & 0.04 & $0.52 \pm$ & 0.07 & $0.66 \pm$ & 0.09 & $0.59 \pm$ & 0.04 \\
\hline Antipyrine half-life (h) & $12 \cdot 5 \pm 0.8$ & $29.8 \pm$ & $3 \cdot 3^{*}$ & $22 \cdot 1 \pm$ & $3.9 *$ & $16.9 \pm$ & $2 \cdot 6^{*}$ & $20.8 \pm$ & $1.4^{*}$ & $24 \cdot 2 \pm$ & $3 \cdot 6^{*}$ \\
\hline
\end{tabular}

Mean \pm SEM $\quad{ }^{*} \mathrm{P}<0.05$ compared with control. 
Table 5 Correlation coefficient for relationships between antipyrine clearance and indices of hepatic function in 29 patients with chronic liver disease of varied aetiology

\begin{tabular}{lll}
\hline & $r$ value & $P<$ \\
\hline Serum albumin & +0.58 & 0.001 \\
Prothrombin index & +0.43 & 0.02 \\
Serum glutamic oxolacetic & -0.19 & NS \\
$\quad$ transaminase & -0.04 & NS \\
Serum bilirubin & +0.26 & NS \\
Alkaline phosphate & & \\
\hline
\end{tabular}

Antipyrine clearance correlated significantly with liver volume in normal subjects (Fig. 2) and also in patients with alcoholic cirrhosis $(r=+0.90$, $P<0.002)$ but not in other groups of patients with liver disease. The increases in liver volume together with a moderate reduction in antipyrine clearance in the patients with liver disease allowed a clear-cut separation from normal subjects (Fig. 2). When antipyrine clearance alone is considered, $48 \%$ of patients with liver disease had antipyrine clearances within the observed normal range-that is, 20-60 $\mathrm{ml} / \mathrm{min}$. However, when antipyrine clearance was normalised for liver volume to provide a measure of the specific activity of drug metabolism in the liver, there was a complete separation in each subgroup of liver disease from normal (Fig. 3).

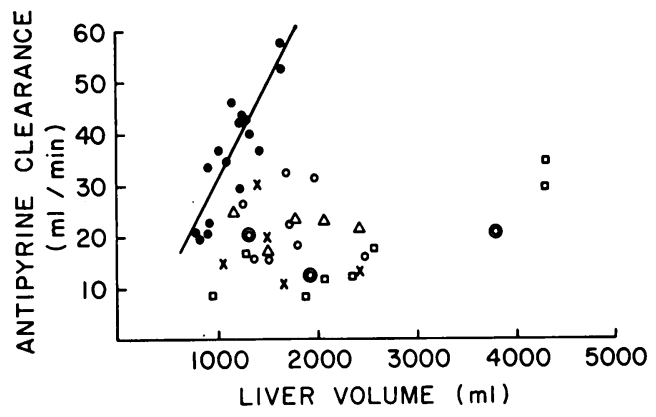

Fig. 2 The relationship between liver volume measured by ultrasound and antipyrine clearance in normal subjects (O) patients with cryptogenic cirrhosis $(O)$, alcoholic cirrhosis $(\square)$, primary hepatoma (O), primary biliary cirrhosis $(\triangle)$ and extrahepatic biliary obstruction $(x)$. The relationship between liver volume and antipyrine clearance in normal subjects was significant. (Antipyrine clearance $=-6.6+0.037$ liver volume, $r=0.87, \mathrm{P}<0.001)$.

\section{Discussion}

Three major observations can be drawn from the present study. Firstly, the liver has to increase in size to a considerable degree before hepatomegaly

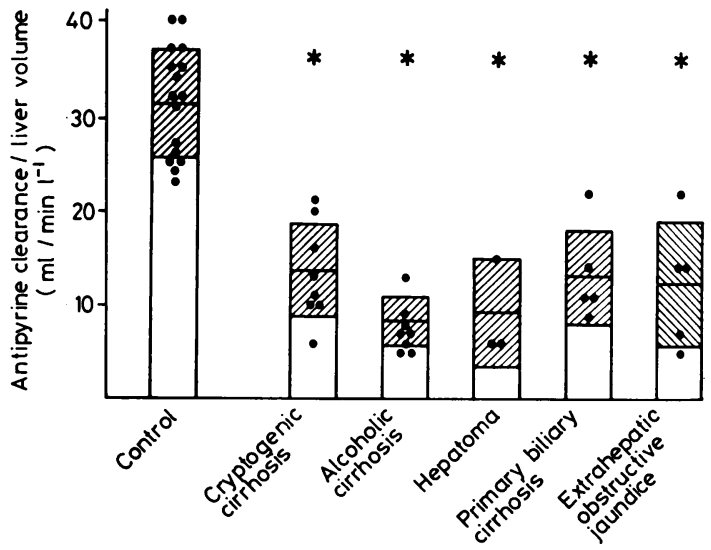

Fig. 3 Antipyrine clearance normalised for liver volume in normal subjects and patients with a variety of chronic liver diseases. Mean $\pm S D .{ }^{*} P<0.001$.

can be detected clinically. Secondly, the measurement of antipyrine clearance per unit volume of liver provides a discrimimating parameter which differentiates patients with liver disease from normal subjects, and, thirdly, the pathophysiological consequences of liver disease on antipyrine pharmacokinetics appear to be similar, irrespective of the nature of underlying chronic liver disease.

In normal subjects, liver size is a function of body weight, representing approximately $1.8 \%$ in the present study. The association between body weight and liver volume in normal subjects enables the expected liver size of patients with liver disease to be estimated. It is appreciated that this would underestimate liver mass in patients with impaired nutrition and overestimate liver mass in patients with sodium retention. However, it does allow an approximation of the degree of hepatomegaly required for the liver to be palpable on physical examination (Table 2). Because of the protected site of the liver above the costal margin, considerable three dimensional enlargement was required, with an overall increase in size of approximately $20 \%$ before the liver became palpable. A liver edge $3 \mathrm{~cm}$ below the costal margin was associated with approximately $70 \%$ increase in volume and a liver edge lower than $3 \mathrm{~cm}$ below the costal margin was associated with an increase in excess of three-fold of normal liver size. As was to be expected in patients of varying build, the absolute size of the liver did vary for any clinical estimate of liver size (Sullivan et al., 1976).

It is well recognised that the normal variation between subjects in the clearance of drugs that are metabolised by the liver is wide (Vesell, 1972). This was clearly supported by the three-fold range in the 
antipyrine clearances in normal subjects, which ranged from 20 to $60 \mathrm{ml} / \mathrm{min}$. However, liver volume also varied by approximately two-fold in these same subjects. The relationship between these two parameters (Fig. 1) suggested that differences between subjects in antipyrine clearance could be attributed to (1) variation in the specific activity of drug metabolising activity and (2) the total mass of the liver in normal subjects.

The range of variation in antipyrine clearance was illustrated by the extent of overlap between normal subjects and patients with liver disease, in that, even though the mean antipyrine clearance in patients with chronic liver disease was significantly lower than the mean control value in each diagnostic group of liver disease (Table 4), when all the patients with chronic liver disease were considered as a single group, $48 \%$ had values within the range observed in normal subjects (Fig. 2). In contrast, when antipyrine clearance was normalised by liver volume, not only was the mean normalised clearance in patients with liver disease different from the mean observed in normal subjects, but the range of normalised clearances in each group did not overlap (Fig. 3). Thus, antipyrine clearance expressed as specific activity provides a high degree of discrimination in differentiating between normal subjects and patients with liver disease. This reduction in specific activity of hepatic drug metabolising ability is consistent with the reductions in cytochrome $\mathbf{P}_{450}$ and drug metabolising activity that have been observed in liver biopsies from patients with liver disease (Schoene et al., 1972; Farrell et al., 1976; Sotaniemi et al., 1977).

It has been previously suggested that different aetiologies for chronic liver diseases might influence drug pharmacokinetics to varying extents, depending on the pathophysiology of the disease state and the physiology of drug disposition. For antipyrine, only changes in drug metabolising ability would be expected to be relevant. Although the numbers of subjects in each diagnostic group are small, there does not appear to be any difference in the reduction in specific activity of antipyrine clearance between each of the subgroups studied (Fig. 3). In particular, the depression in drug metabolising activity appeared to be equally marked in patients with intra- and extrahepatic biliary obstruction, as in patients with cryptogenic cirrhosis. These findings are in contrast with those of Hepner and Vesell (1975). However, all the patients with extrahepatic biliary obstruction had underlying carcinoma, and all patients with intrahepatic obstruction had other features of cirrhosis. The results, however, are consistent with the in vitro studies of McLeun and Fouts (1961) who demonstrated inhibition of drug metabolising activity both in animals with biliary obstruction and when bile acids were added to mixed function oxidase enzymes from normal animals.

Only patients with alcoholic cirrhosis tended to have lower specific activity for antipyrine clearance. This was possibly due to the association of fatty infiltration further reducing specific activity. A plausible explanation for the significant correlation $(r=+0.90, \mathrm{P}<0.001)$ between liver volume and antipyrine clearance in these patients with alcoholic cirrhosis is that patients with marked hepatomegaly represent an early stage in the disease process with a normal total hepatic drug metabolising capability. Then, with progression of the disease process, liver volume decreases with the reduced specific activity of drug metabolising activity remaining constant, so that patients with alcoholic cirrhosis and small livers have end-stage disease and a very low total metabolic potential. Similar conclusions can be drawn from the measurement of antipyrine clearance and the hepatic concentration of cytochrome $\mathbf{P}_{450}$ in patients with fatty infiltration and alcoholic cirrhosis (Sotaniemi et al., 1977a).

Only three patients in the present study had primary hepatoma; in each instance the reduction in antipyrine clearance is consistent with previous reports that hepatoma cells are unable to contribute towards drug metabolism (Sotaniemi et al., 1977b).

In conclusion, the relatively non-invasive procedures of measuring in vivo antipyrine clearance and liver volume using ultrasound affords the potential for assessing hepatic function in terms of specific activity. Hopefully, this will provide a probe for evaluating the natural history and effect of therapy in longitudinal studies of patients with liver disease.

We are grateful for the excellent technical assistance of Miss Julia Ford. R. A. B. was supported by National Institutes of Health Grant GM-15431.

\section{References}

Andreasen, P. B., and Greisen, G. (1976). Phenazone metabolism in patients with liver disease. European Journal of Clinical Pharmacology. 6, 21-26.

Andreasen, P. B., and Vesell, E. S. (1974). Comparison of plasma levels of antipyrine, tolbutamide and warfarin after oral and intravenous administration. Clinical Pharmacology and Therapeutics, 16, 1059-1065.

Andreasen, P. B., Ranek, L., Statland, B. E., and Tygstrup, N. (1974). Clearance of antipyrine dependence of quantitative liver function. European Journal of Clinical Pharmacology, 4, 129-134.

Branch, R. A., Herbert, C. M., and Read, A. E. (1973). Determinants of serum antipyrine half-lives in patients with liver disease. Gut, 14, 569-573.

Branch, R. A., James., J., and Read, A. E. (1976a). A study of factors influencing drug disposition in chronic liver 
disease, using the model drug (+)-propranolol. British Journal of Clinical Pharmacology, 3, 243-249.

Branch, R. A., James, J., and Read, A. E. (1976b). The clearance of antipyrine and indocyanine green in normal subjects and in patients with chronic liver disease. Clinical Pharmacology and Therapeutics, 20, 81-89.

Brodie, B. B., and Axelrod, J. (1950). The fate of antipyrine in man. Journal of Pharmacology and Experimental Therapeutics, 98, 97-104.

Brodie, B. B., Axelrod, J., Soberman, R., and Levy, B. B. (1949). The estimation of antipyrine in biological materials. Journal of Biological Chemistry, 179, 25-29.

Farell, G. C., Cooksley, W. G. E., Powell, L. W., and Hart, P. (1976). Interaction between liver disease and chronic drug investigation on hepatic metabolism (Abstract). Gastroenterology, 71, 905.

Hepner, G. W., and Vesell, E. S. (1975). Quantitative assessment of hepatic function by breath analysis after oral administration of $\left[{ }^{14} \mathrm{C}\right]$ aminopyrine. Annals of Internal Medicine, 83, 632-638.

Hoyumpa, A. M., Jr., Branch, R. A., and Schenker, S. (1978). The disposition and effects of sedatives and analgesics in liver disease. Annual Review of Medicine, 29, 205-218.

Kolmodin, B., Azarnoff, D. L., and Sjöqvist, F. (1969). Effect of environmental factors on drug metabolism: Decreased plasma half-life of antipyrine in workers exposed to chlorinated hydrocarbon insecticides. Clinical Pharmacology and Therapeutics, 10, 638-642.

McLuen, E. F., and Fouts, J. R. (1961). The effect of obstructive jaundice on drug metabolism in rabbits. Journal of Pharmacology and Experimental Therapeutics, 131, 7-11.

Noordhoek, J., Wilson, J. H. P., Liem, F., and SavenijeChapel, I. E. M. (1975). Biological half-life and clearance of phenazone in patients with liver disease. Pharmaceutisch Weekblad, 110, 1305-1308.
Roberts, C. J. C., Jackson, L., Halliwell, M., and Branch, R. A. (1976). The relationship between liver volume, antipyrine clearance and indocyanine green clearance before and after phenobarbitone administration in man. British Journal of Clinical Pharmacology, 3, 907-913.

Schoene, G., Fleischmann, R. A., Remmer, H., and Oldershausen, H. F. (1972). Determination of drug metabolizing enzymes in needle biopsies of human liver. European Journal of Clinical Pharmacology, 4, 65-73.

Sotaniemi, E. A. Ahlqvist, J., Pelkonen, R. O., Pirltiaho, H., and Luoma, P. V. (1977a). Histological changes in the liver and indices of drug metabolism in alcoholics. European Journal of Clinical Pharmacology, 11, 295-303.

Sotaniemi, E. A., Pelkonen, R. O., Mokka, R. E., Huttunen, R., and Viljakainen, E. (1977b). Impairment of drug metabolism in patients with liver cancer. European Journal of Clinical Investigation, 7, 269-274.

Sullivan, S., Krasner, N., and Williams, R. (1976). The clinical estimation of liver size: a comparison of techniques and an analysis of the source of error. British Medical Journal, 2, 1042-1043.

Vesell, E. S. (1972). Pharmacogenetics New England Journal of Medicine, 287, 904-909.

Vesell, E. S., and Page, J. G. (1968). Genetic control of drug levels in man: antipyrine. Science, 161, 72-73.

Vestal, R. E., Norris, A. H., Tobin, J. D., Cohen, B. H., Shock. N. W., and Andres, R. (1975). Antipyrine metabolism in man: influence of age, alcohol, caffeine and smoking. Clinical Pharmacology and Therapeutics, 18, 425-432.

Wilkinson, G. R., and Schenker, S. (1975). Drug disposition and liver disease. Drug Metabolism Reviews, 4, 139-175.

Wilkinson, G. R., and Shand, D. G. (1975): A physiological approach to hepatic drug clearance. Clinical Pharmacology and Therapeutics, 18, 377-390. 